\title{
Hot corrosion behavior of HVOF-sprayed CoNiCrAIYSi coatings in a sulphate environment
}

\author{
Kang Yuan, Ru Lin Peng, Xin-Hai Li, Sten Johansson and Yandong Wang
}

\section{Linköping University Post Print}

\section{Tweet}

N.B.: When citing this work, cite the original article.

Original Publication:

Kang Yuan, Ru Lin Peng, Xin-Hai Li, Sten Johansson and Yandong Wang, Hot corrosion behavior of HVOF-sprayed CoNiCrAlYSi coatings in a sulphate environment, 2015, Vacuum, Volume 122, Part A, pp. 47-53.

http://dx.doi.org/10.1016/j.vacuum.2015.09.015

Copyright: Elsevier

http://www.elsevier.com/

Postprint available at: Linköping University Electronic Press

http://urn.kb.se/resolve?urn=urn:nbn:se:liu:diva-111117 


\section{Hot corrosion behavior of HVOF-sprayed CoNiCrAlYSi coatings in a sulphate environment}

Kang Yuan ${ }^{1, *}$, Ru Lin Peng ${ }^{1}$, Xin-Hai Li ${ }^{2}$, Sten Johansson

${ }^{1}$ Department of Management and Engineering, Linkoping University, SE-58183 Linkoping, Sweden

${ }^{2}$ Siemens Industrial Turbomachinery AB, SE-61283 Finspang, Sweden

*Corresponding author: Tel: +46(0)13284696, Fax: +46(0)13282505, E-mail: kang.yuan@liu.se

Abstract.

HVOF-sprayed CoNiCrAlYSi coatings were tested at $900{ }^{\circ} \mathrm{C}$ in a hot corrosion environment containing sodium-potassium sulphates. The HVOF spraying caused the typical splat-on-splat structure. The results after the hot corrosion testing showed that the corrosion preferentially occurred at the coating surface and the splat boundaries. The oxidation along the splat boundaries can isolate the splat from the underlying coating matrix. In those isolated splats or coating parts, internal oxidation and nitridation of $\mathrm{Al}$ took place, following that the Al-depleted coating fragments were then oxidized to spinels. For those coatings which had a worse splat boundary quality (i.e. with higher porosity and intersplat oxides) or had a worse coating surface quality (i.e. with more small coating fragments therefore more interfaces), heavier corrosion attack was observed on those coatings due to the corrosion of the splats or the coating fragments. The results indicated that the as-sprayed coating quality including porosity and surface morphology was important for the hot-corrosion resistance of the coatings. 
Keywords: Hot Corrosion; Sulphate; MCrAlY; HVOF.

\section{Introduction}

Since the development of gas turbines is moving towards further increase in turbine efficiency, longer service intervals and higher reliability, various coating systems are introduced to the turbines, such as the high temperature protective coatings, like MCrAlY ( $\mathrm{M}$ for $\mathrm{Ni}, \mathrm{Co}$, or a combination thereof), are applied in turbines to protect the hot components from hot corrosion attack. Hot corrosion usually occurs when the alloys or coatings expose to the high temperature in an environment containing molten salts, typically sulphates in gas turbine applications [1]. Hot corrosion on MCrAlY coatings has been largely investigated in sulphate-containing environments by focusing on the degradation of oxide scales [2-4]. The performance of the coatings in the hot corrosion environments is related to a number of factors like composition and microstructure of the coatings, surrounding atmosphere (gases), corrosive salts, exposure time and temperature [4-6].

Thermal spraying techniques have been widely applied to produce MCrAlY coatings, such as by vacuum plasma spray (VPS), air plasma spray (APS), low pressure plasma spray (LPPS), and High-velocity oxy-fuel (HVOF) [7-9]. HVOF technique has caught a great attention in industry applications in the last two decades since it can make a very dense coating (porosity $<3 \%$ ) with a relatively low cost (especially comparing with VPS process) [10]. HVOF process creates typical splat-on-splat structure in the coatings, and the coatings' performance, especially in a corrosive 
environment, can be strongly influenced by such structure. Some investigations showed that the splat boundary was usually the weakest part in corrosive environments since the corrosion generally started from the defects like pores, inclusions and cracks at the splat boundaries [11-13]. Some other researches further suggested that one may improve the corrosion resistance of the HVOF coatings by reducing the amount of those intersplat defects through adjusting the parameters in the thermal spraying process or operating some pre-testing heat treatments $[11,12,14]$. The splat structure may also affect the coating performance at the elevated temperatures in hot corrosion environments, the research on that, however, has not been well deeply carried out in HVOF-sprayed MCrAlY coatings so far.

In this study, some CoNiCrAlYSi coatings sprayed by HVOF were tested in a sodium-potassium-sulphate environment at $900{ }^{\circ} \mathrm{C}$. The aim of this paper was to investigate how the coating quality (porosity, intersplat oxidation, and surface quality) affected the hot corrosion behaviour of the HVOF coatings.

\section{Experimentals}

Spherical powder $(-53+26 \mu \mathrm{m})$ was used to produce three MCrAlY coatings with similar composition (B0, B1, B2) on Ni-based superalloy Inconel 792. The powder was produced in a vacuum atmonization reactor in an industrial company (the manufacturer). Compressed argon gas puffed MCrAlY melts away into powders in the reactor. The MCrAlY powders were cooled, collected and screened, and were then used to manufacture MCrAlY coatings by JP5000 HVOF gun. The spray parameters used were oxygen flow rate $900 \mathrm{l} / \mathrm{min}$ with pressure of $1.5 \mathrm{MPa}$, fuel (Kerosene) flow rate 32 $1 / \mathrm{h}$, carrier gas $\left(\mathrm{N}_{2}\right)$ flow rate $81 / \mathrm{min}$ with pressure of $0.3 \mathrm{MPa}$, spray distance about 380 
$\mathrm{mm}$, powder feed rate $75 \mathrm{~g} / \mathrm{min}$. The coating samples were heat-treated in the processes including solution treatment at $1120^{\circ} \mathrm{C}$ for 2 hours in vacuum and ageing at $845^{\circ} \mathrm{C}$ for 24 hours in air. The nominal composition of the coatings and the superalloy substrate is listed in Table I. The addition of some heavy elements (Ta, Ru and Ir) in the coatings was mainly aimed at improving the mechanical properties of the coatings, and the corresponding investigation will be carried out in future.

Table I. Nominal composition (wt.\%) of the MCrAlY coatings (B0, B1 and B2) and the substrate (Inconel 792).

\begin{tabular}{llllllllllllll}
\hline & $\mathrm{Ni}$ & $\mathrm{Co}$ & $\mathrm{Cr}$ & $\mathrm{Al}$ & $\mathrm{Y}$ & $\mathrm{Si}$ & $\mathrm{Ta}$ & $\mathrm{Ti}$ & $\mathrm{W}$ & $\mathrm{Mo}$ & $\mathrm{Ru}$ & $\mathrm{Ir}$ \\
\hline B0 & 30 & Bal. & 20 & 10 & 0.6 & 0.5 & - & - & - & - & - & - \\
B1 & 30 & Bal. & 20 & 10 & 0.6 & 0.5 & 0.5 & - & - & - & 0.5 & - \\
B2 & 30 & Bal. & 20 & 10 & 0.6 & 0.5 & - & - & - & - & - & 0.5 \\
Inconel 792 & Bal. & 9 & 12.5 & 3.4 & - & - & 4.2 & 4.0 & 4.2 & 1.9 & - & - \\
& & & & & & & & & & & & &
\end{tabular}

The hot corrosion testing was carried out in a lab-made corrosion rig in which the temperature was set at $900{ }^{\circ} \mathrm{C}$. A solution containing water and $(0.8 \mathrm{Na}, 0.2 \mathrm{~K})_{2} \mathrm{SO}_{4}(1$ mol/L) was sprayed onto the coating surfaces before the samples were moved into the furnace. The sulphate deposition was controlled to be about $960 \mu \mathrm{g} / \mathrm{cm}^{2}$ at the coating surface. After one-time exposure at $900{ }^{\circ} \mathrm{C}$ for 48 hours, the samples were moved out of the furnace, air-cooled down to about $100{ }^{\circ} \mathrm{C}$, and then sprayed with the solution again 
for another 48-hour hot corrosion process. For more details of the corrosion rig, see Ref. [15].

The morphologies of the coating surfaces and cross sections of the coatings after the hot corrosion testing were analyzed in a scanning-electron microscope (SEM) Hitachi SU70. Phase identification was performed using X-ray diffraction (XRD) with $\mathrm{Cr}-\mathrm{K} \alpha$ radiation. The chemical composition of the coatings was measured by an energydispersive spectroscopy (EDS) and a wavelength-dispersive spectroscopy (WDS) system from Oxford instruments in the SEM.

3 Results

\subsection{Coatings before hot corrosion}

Cross sections of the three coatings after the solution and ageing heat treatment are shown in Fig. 1. There were two main metallic phases in the coatings: $\gamma$ and $\beta$. Scanning electron microscopy also revealed $\sigma-\mathrm{CrCo}$ and $\alpha-\mathrm{Cr}$ in small amount. Image analyses indicated that the volume fraction of the pores plus the intersplat oxides (the dark features as pointed by the arrows) was about $0.34 \%( \pm 0.24 \%$, the measuring standard variation) in $\mathrm{B} 0,1.04 \%( \pm 0.34 \%)$ in $\mathrm{B} 1$, and $0.59 \%( \pm 0.45 \%)$ in $\mathrm{B} 2$, indicating that B0 had a slightly better splat interface quality than B1 and B2. The intersplat oxides were mainly $\mathrm{Al}$ or $\mathrm{Y}$ rich according to EDS measurement (see also our previous work in Ref. [16]). In addition, the quality of coating B2' surface was poorer than B0 and B1; more small coating fragments can be seen at coating B2's surface (Fig. 1c). Such coating fragments provided additional interfaces or boundaries. The reason for causing the difference of the porosity (and intersplat oxide) and the amount of the surface 
fragments among the coatings was not clear, but probably was due to an instability of the spray process. The reason needs to be further investigated in future.

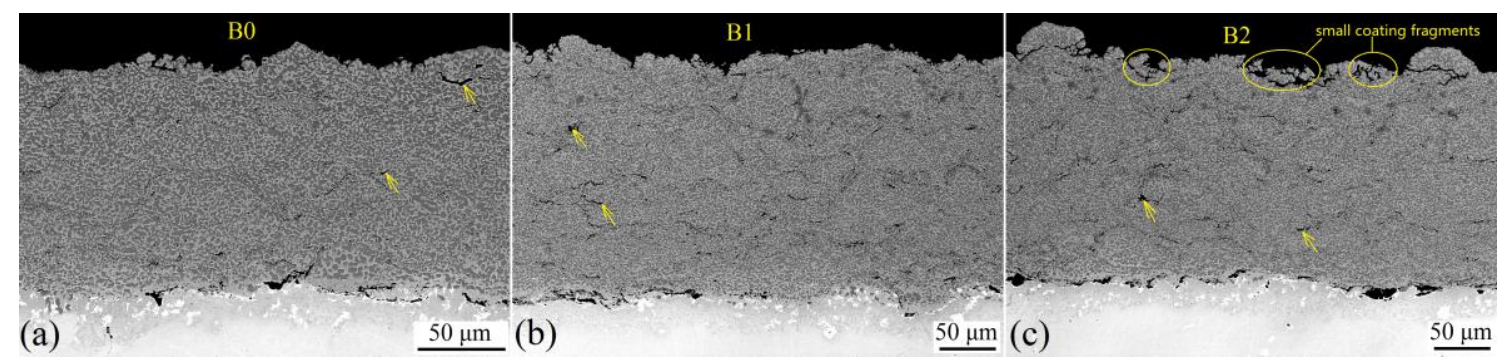

Figure 1. Cross sections of the coatings after the solution and ageing heat treatments. The arrows mark some pores or intersplat oxides along splat boundaries.

\subsection{Hot corrosion testing of the coatings}

The hot corrosion attack on the coatings was evaluated from the XRD results and the microstructure of the coatings. As shown in Fig. 2, alumina and $\mathrm{MCr}_{2} \mathrm{O}_{4}$ spinels ( $\mathrm{M}$ for $\mathrm{Ni}$ or $\mathrm{Co}$ ) were the main corrosion products detected by XRD at the coating surfaces. Those spinels had a wide range of composition (in at.\%): 50-60 O, 2-10 Al, 15-24 Cr, 5-10 Co and 3-6 Ni. In Fig. 2, there is a clear increase in intensity of alumina and spinel peaks in coating B1 and B2 from 6 cycles to 10 cycles, indicating that accelerated corrosion occurred during those testing cycles. The change in B0 was not as large as in $\mathrm{B} 1$ and $\mathrm{B} 2$. The formation of $\mathrm{MCr}_{2} \mathrm{O}_{4}$ spinels was due to the oxidation of the coating elements $\mathrm{Ni}, \mathrm{Co}$ and $\mathrm{Cr}$. The $\mathrm{MCr}_{2} \mathrm{O}_{4}$ peak was wider in $\mathrm{B} 2$ coating than in $\mathrm{B} 1$ than in B0, indicating B2 coatings got the heaviest corrosion attack. That could be related to the fact that $\mathrm{B} 2$ had a high porosity and more surface fragments. 


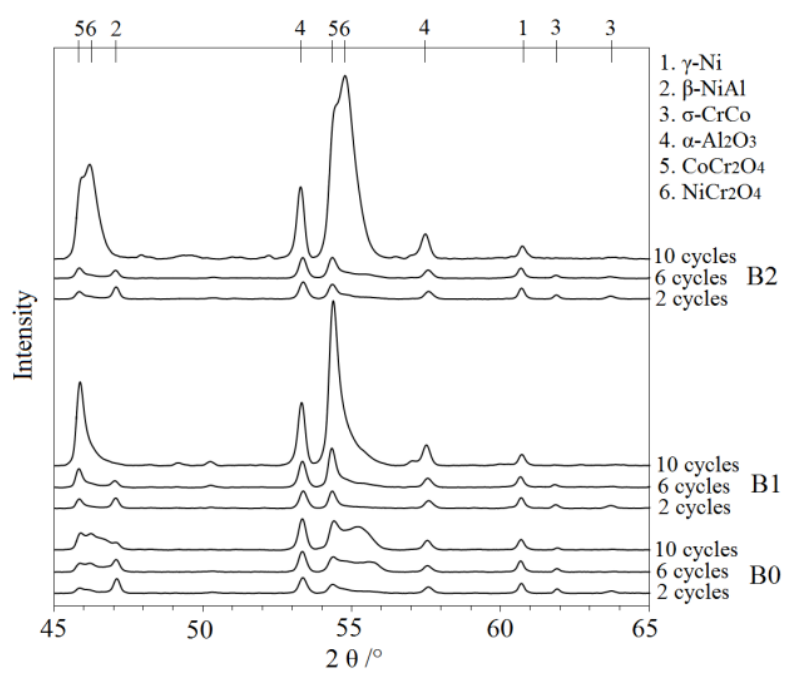

Figure 2. XRD spectra from a measurement on the coating surfaces after the hot corrosion. The intensities of the spectra have been normalized by the peaks of $\gamma$-Ni phase.

Fig. 3 to 5 show the cross sections of the oxide layers in coating B0 (Fig. 3), B1 (Fig. 4) and B2 (Fig. 5) for different number of cycles. The oxide layers formed at the coating surfaces mainly consisted of an Al-rich oxide scale and some spinels on top of the scale. It can be seen that the oxide layer development was slow during the first 6 cycles. The Al-oxide scales thickened much after 10 cycles, especially on B1 and B2; this was confirmed by measured thickness of the scale (Fig. 6a) and the thickness of $\beta$ depleted zone which formed beneath the scale (Fig. 6b). The results in Fig. 6 also agreed with the XRD measurement (Fig. 2), i.e. that the accelerated hot corrosion occurred after 6 cycles and heavier corrosion occurred in B1 and B2 coatings than in B0. 


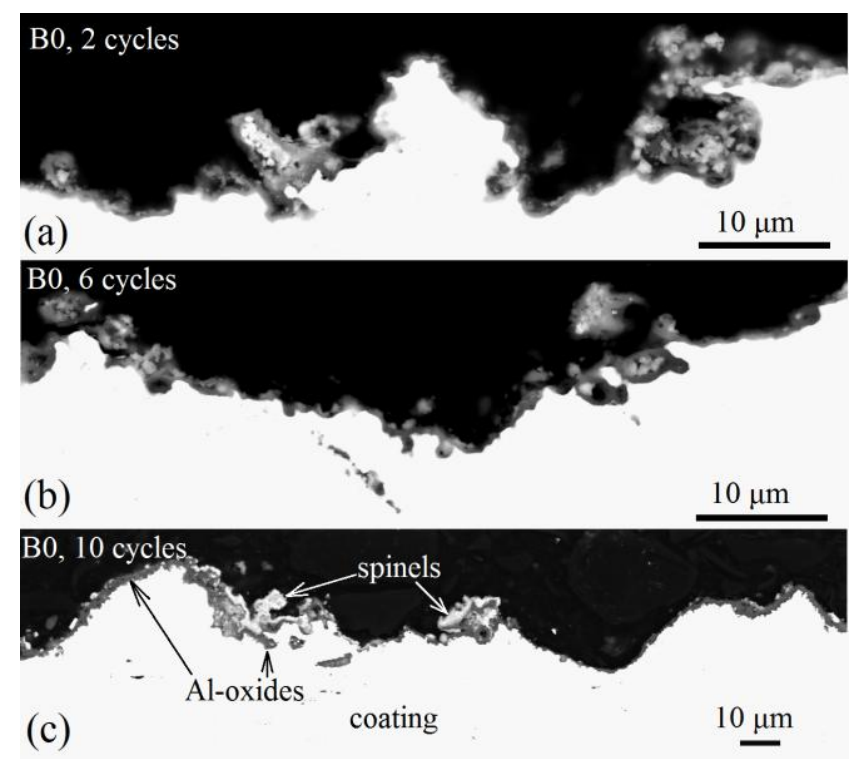

Figure 3. Morphology of the oxide layers formed on B0 in the hot corrosion.

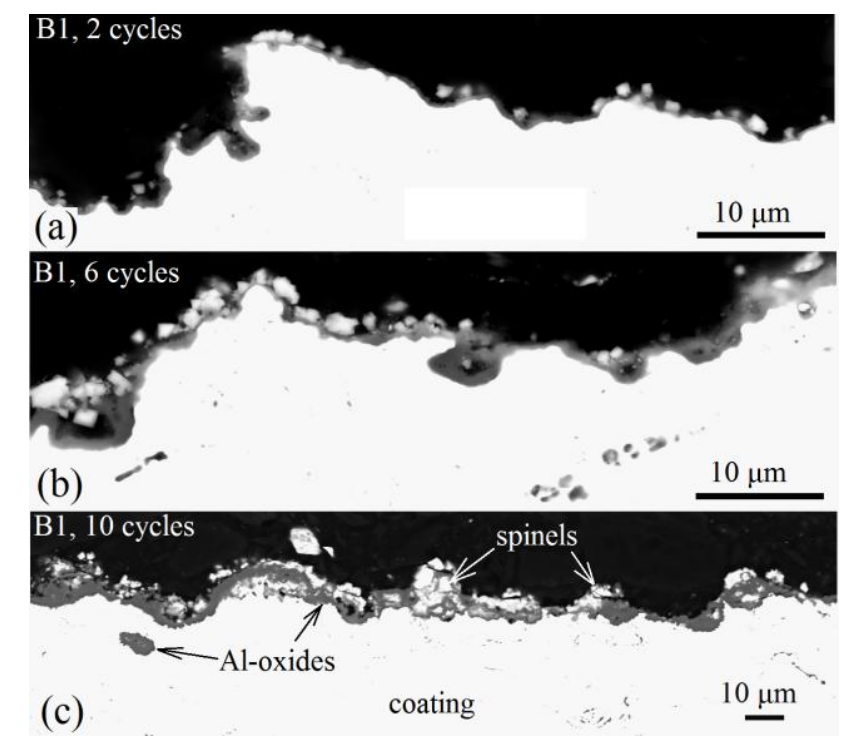

Figure 4. Morphology of the oxide layers formed on B1 in the hot corrosion. 

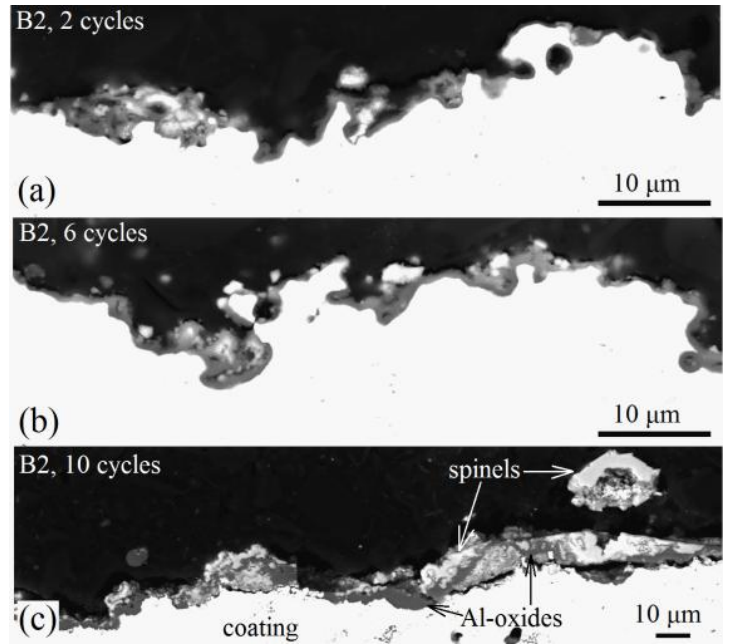

Figure 5. Morphology of the oxide layers formed on B2 in the hot corrosion.
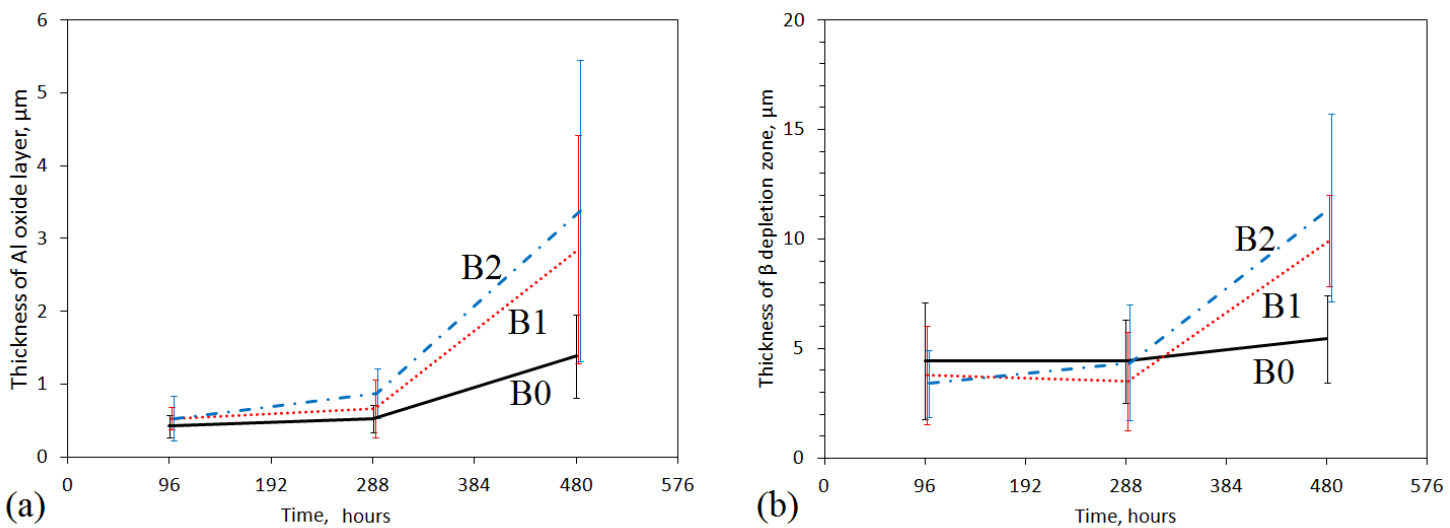

Figure 6. Development of the thickness of Al-rich oxide scale and $\beta$-depleted zone in the coatings. The error bars were derived from a statistical measurement through the cross sections of the coatings (10 statistically selected coating positions were measured). To clearly show the error bars, the curves of B1 and B2 are move rightwards a bit.

According to the SEM and EDS investigation, the Al-rich oxide scale was not pure alumina $\left(\alpha-\mathrm{Al}_{2} \mathrm{O}_{3}\right)$. Furthermore, the morphology of the scale was also different from a pure alumina formed in an oxidation process. As shown in Fig. 7, the Al-oxide 
scale formed in the hot corrosion environment (for 10 cycles, about 480 hours at $900{ }^{\circ} \mathrm{C}$ ) had smaller grain size and was thicker than the pure alumina scale formed in a lab-air oxidation process (for 500 hours) which had a typical columnar structure. The morphology of the small-grain Al-rich oxides may have formed due to a fluxing process of alumina $[17,18]$. It is also worth mentioning that multi-layers of the Al-rich oxides could be observed in some areas where the coating was locally heavily attacked, indicating that buckling and reformation of alumina scales had occurred during the cyclic hot corrosion testing.

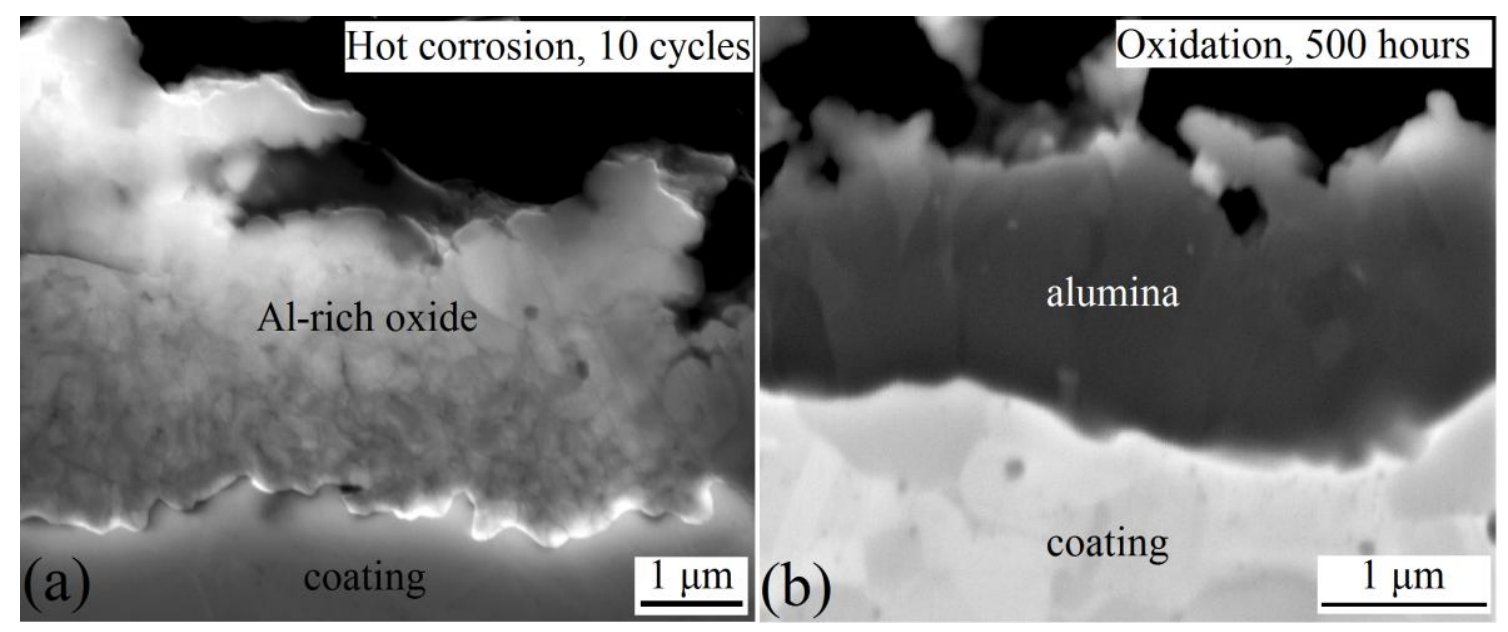

Figure 7. Typical morphology of (a) an Al-rich oxide scale in the hot corrosion $\left(900^{\circ} \mathrm{C}, 10\right.$ cycles) and (b) an pure alumina scale formed in the oxidation in air $\left(900^{\circ} \mathrm{C}, 500\right.$ hours $)$.

Fig. 8 shows a local area in coating B2 after 10 cycles of hot corrosion. At such local coating surface, Al-oxide layer ("n") was spalled off. Oxygen and nitrogen from the atmosphere can easily diffuse into the coating to cause internal oxidation (" 1 ") and nitridation ("2"). The internal oxidation and nitridation further consumed the $\mathrm{Al}$ in the $\beta$-depleted zone, leaving some coating fragments poor in Al (“4”) near the coating 
surface. Close to the coating fragments, some Cr-Co-Ni spinel oxides ("3") formed which were the products of further oxidation of the coating fragments. The formation of spinels may also have started from oxidation at the coating splat interface, as shown in Fig. 9a. Due to oxidation, the splat was isolated from the underlying coating matrix which blocked outward diffusion of $\mathrm{Al}$ from the coating matrix. With further oxidation of $\mathrm{Al}$ from the isolated splat, the splat/coating fragments became Al-poor and further oxidized to form spinels, as shown in Fig. $9 \mathrm{~b}$.

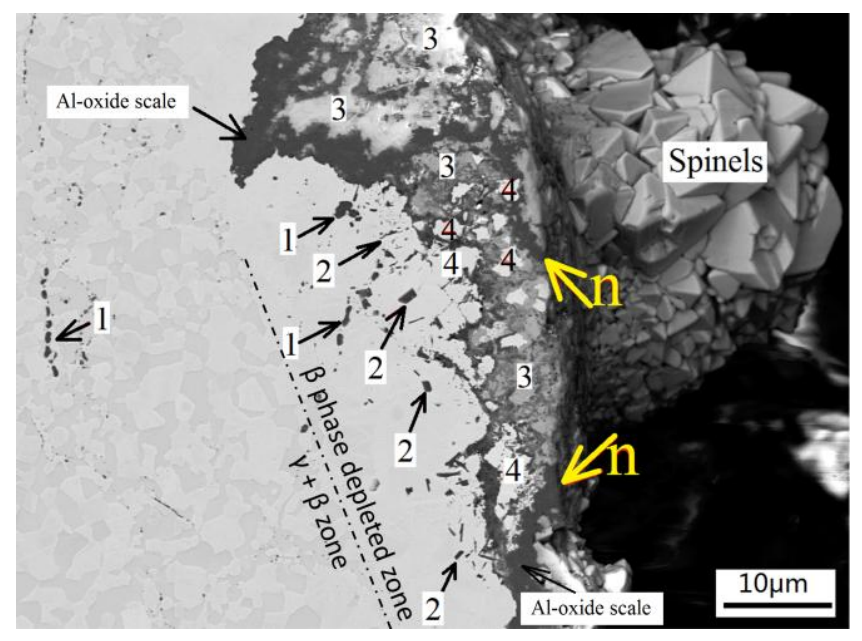

Figure 8. Morphology of the oxide layer at the coating surface of B2 for 10 cycles. "1" is for internal Al-oxides, "2" is for Al-nitrides, " 3 " is for Cr-Co-Ni-rich oxides, " 4 " is for isolated coating fragments, and " $\mathrm{n}$ " marks the spallation of Al-oxide scale. The coating surface is on the right side. The identification of the oxide/nitride phases was based on EDS/WDS point scans. 

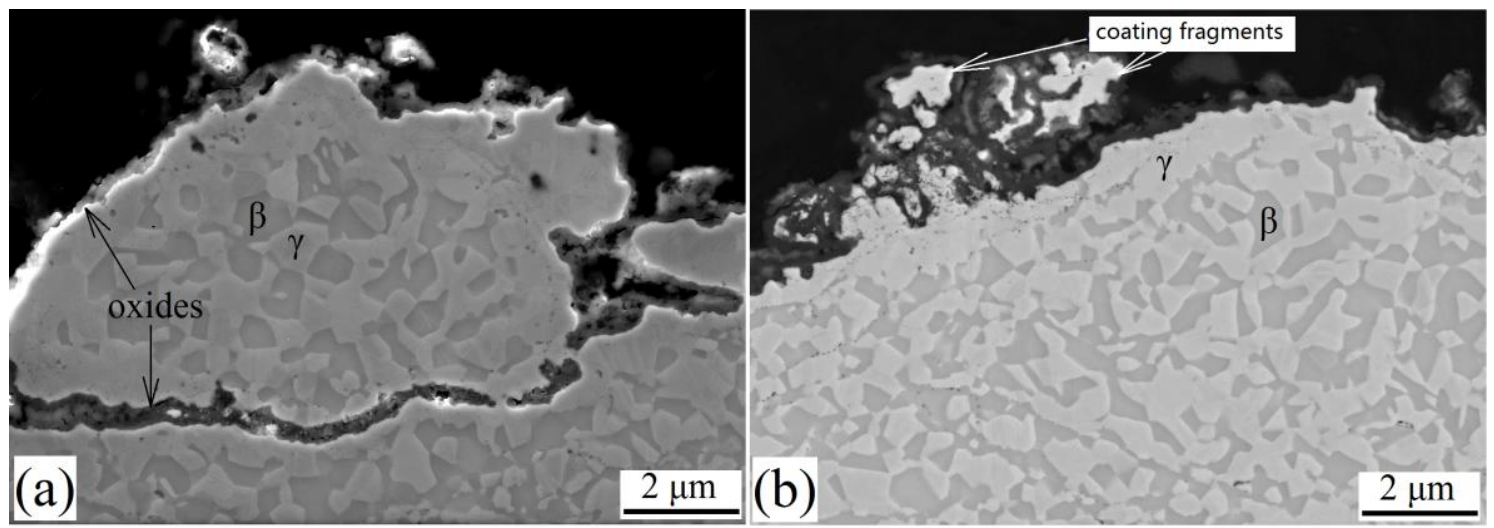

Figure 9. Morphology of the cross sections of B0 in the hot corrosion for 6 cycles, showing (a) corrosion along splat boundary, and (b) isolation of some coating fragments from the coating matrix.

Fig. 10 compares the surface morphology of the three coatings after 10 cycles; the images were taken under the same SEM setting-ups. In the backscattered-electron contrast, the bright features mainly represent $\mathrm{Cr}$-Co-Ni-rich spinels while the darker ones represent alumina. Obviously, B0 contained the smallest amount of spinels at the surface while B2 had the highest. Such conclusion agreed with the XRD results in Fig. 2.

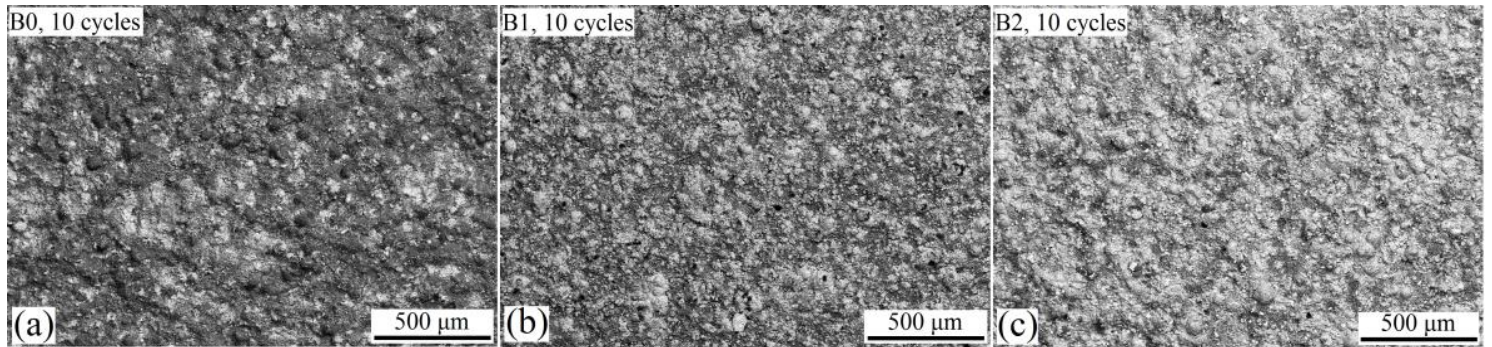

Figure 10. Backscattered-electron images showing the morphology of the coating surfaces after the hot corrosion for 10 cycles. The bright features in the images are mainly $\mathrm{Cr}-\mathrm{Co}-\mathrm{Ni}$ rich spinels, and the darker features are mainly alumina. 
Fig. 11 to 13 present the EDS mapping results of cross sections of the oxide layers which formed in some heavily corroded areas in the three coatings after 10-cycle hot corrosion. Those oxide layers were mainly a mixture containing Al-rich oxides, probably alumina, and $\mathrm{Cr}-\mathrm{Co}-\mathrm{Ni}$-rich oxides, probably spinels. Other phases, for instance Si- or Y-rich phases, may also form. Na was also detected in the oxide layers, probably indicating the fluxing of the oxide layer in the sulphate environment $[17,18]$.

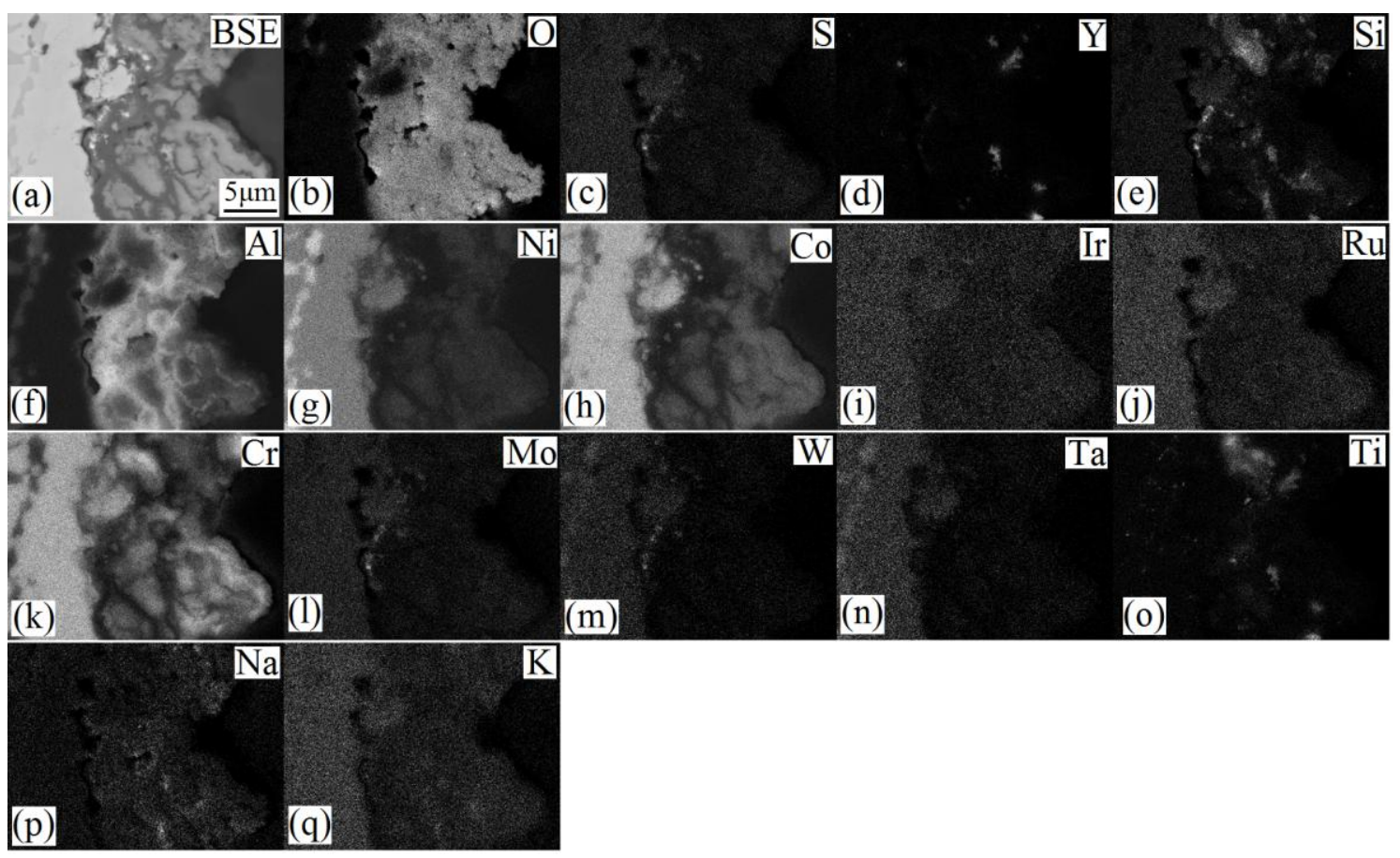

Figure 11. EDS mapping on the cross section of the oxide layer in B0 after the hot corrosion for 10 cycles. The coating surface is on the right side. 


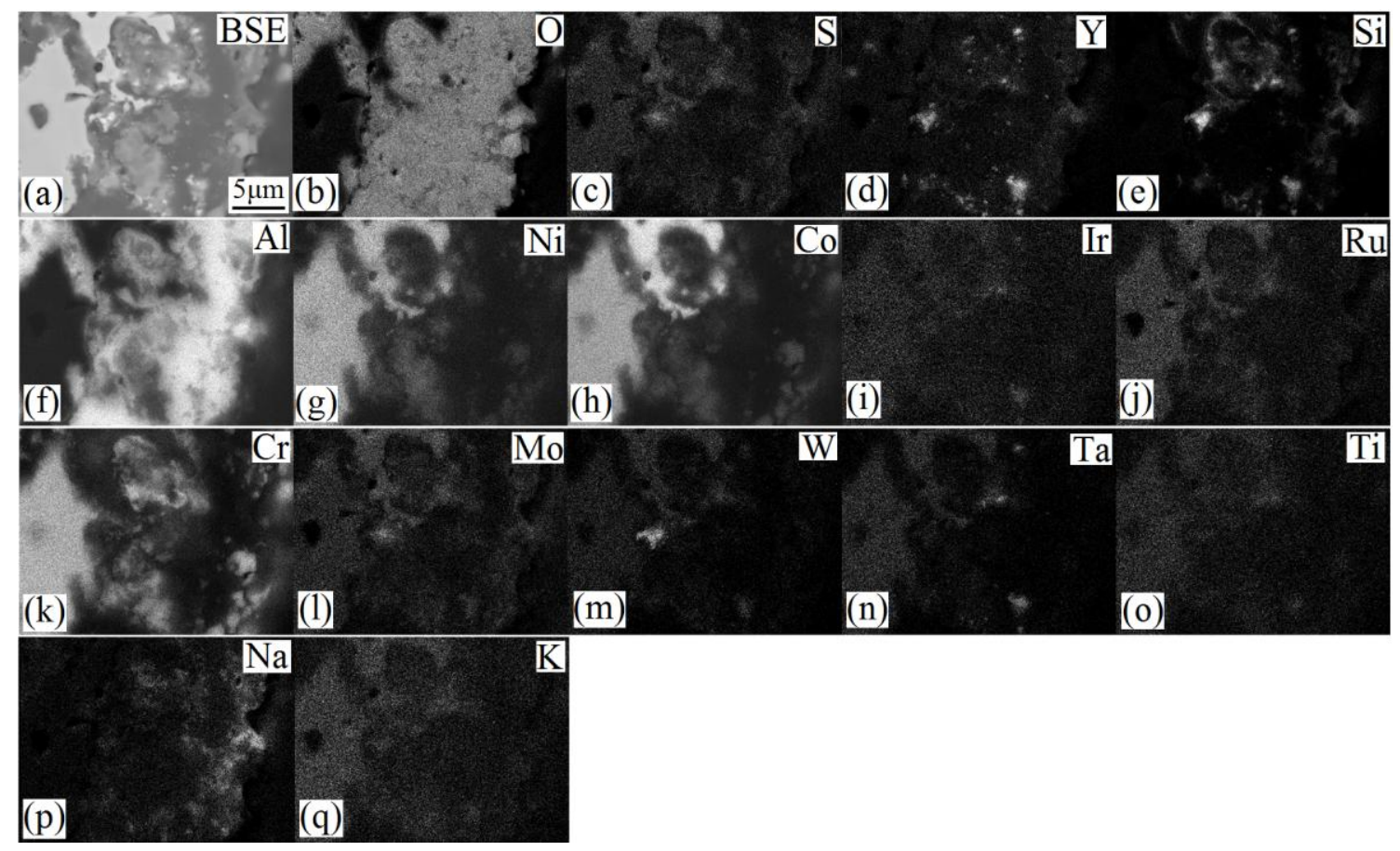

Figure 12. EDS mapping on the cross section of the oxide layer in B1 after the hot corrosion for 10 cycles. The coating surface is on the right side.

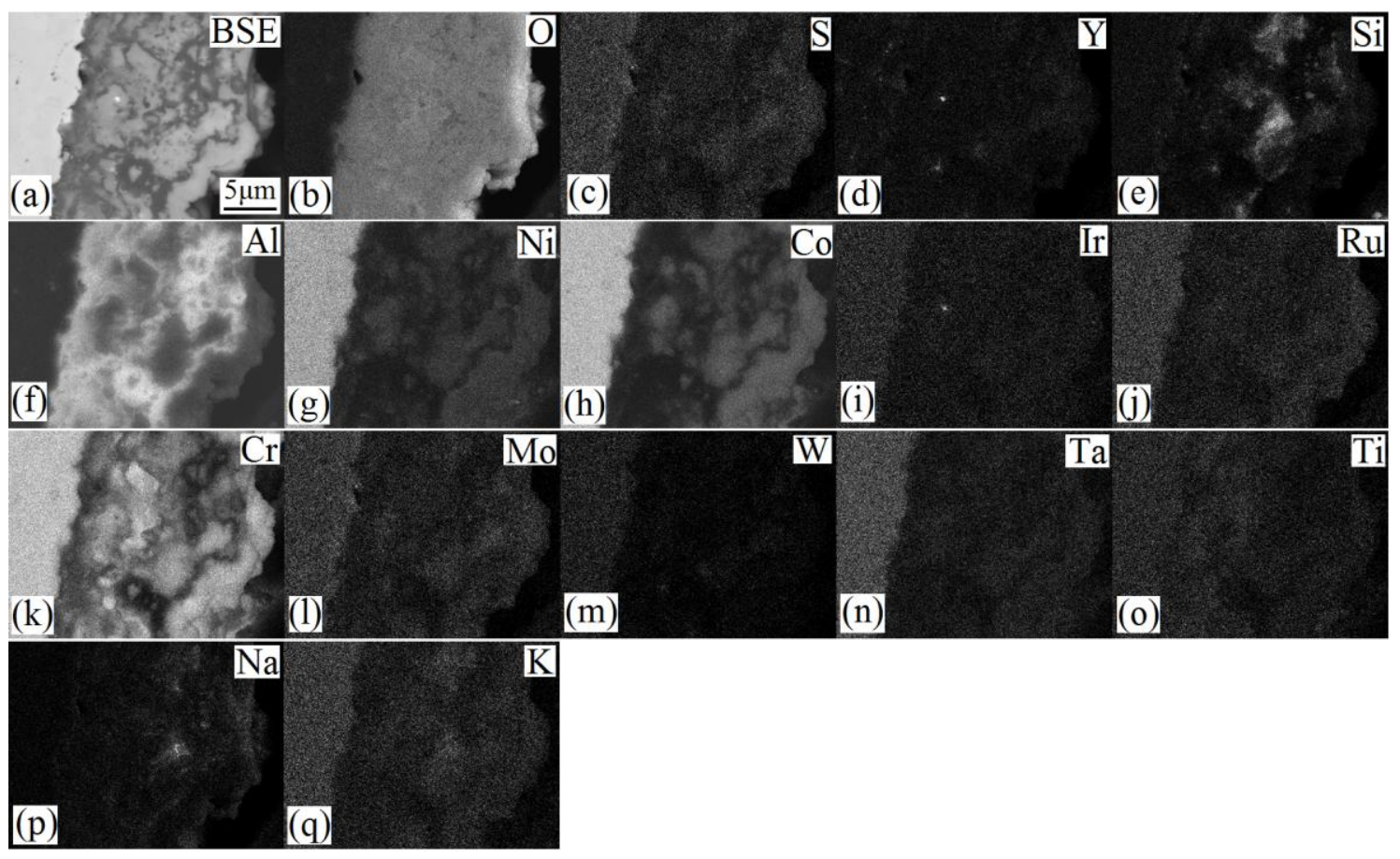


Figure 13. EDS mapping on the cross section of the oxide layer in B2 after the hot corrosion for 10 cycles. The coating surface is on the right side.

The three MCrAlY coatings used in the hot corrosion testing had very similar composition but with a slightly concentration difference of some heavy elements, i.e. Ta, $\mathrm{Ru}$ and Ir. According to the EDS maps in Fig. 12 and 13, Ta, Ru or Ir mainly stayed in the coatings. Those elements were also slightly detected in the oxide layer, dissolved in the spinel phases. The spinel phases were mainly formed due to the oxidation of the Aldepleted coating fragments. In the oxide layer shown in Fig. 14, an Ir-rich metallic particle was found surrounded by $\mathrm{Cr}-\mathrm{Co}-\mathrm{Ni}$-rich oxides, indicating that Ir was the last element to be oxidized in the coating. According to our more detailed SEM and EDS work, Ta, Ru and Ir did not form other oxides or phases at the coating surfaces and were only detected in the spinel phases or in un-oxidized coating fragments, indicating that these heavy elements were inactive during the hot corrosion process. In addition, $\mathrm{Ru}$ and Ir preferred to dissolve in $\beta$ phase in the coating matrix. As shown in Fig. 15, the concentration of $\mathrm{Ru}$ or Ir in the $\beta$ phase was about two to three times higher than that in the $\gamma$ phase.

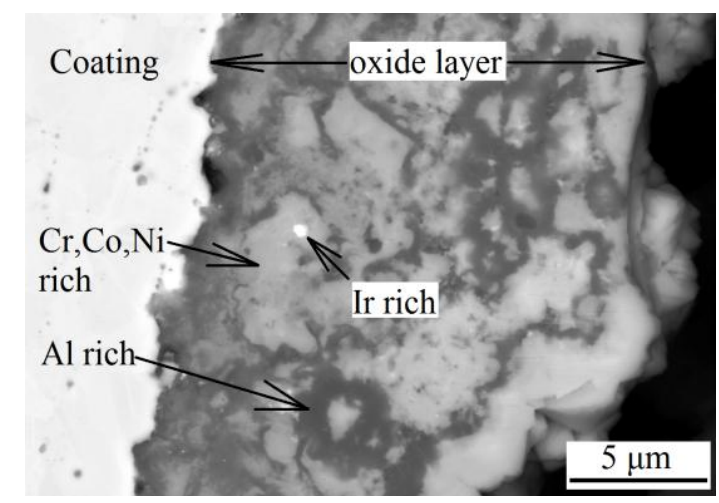


Figure 14. Morphology of part of the mixed oxide layer on B2 after the hot corrosion for 10 cycles. The corresponding EDS mapping results are shown in Fig. 13.

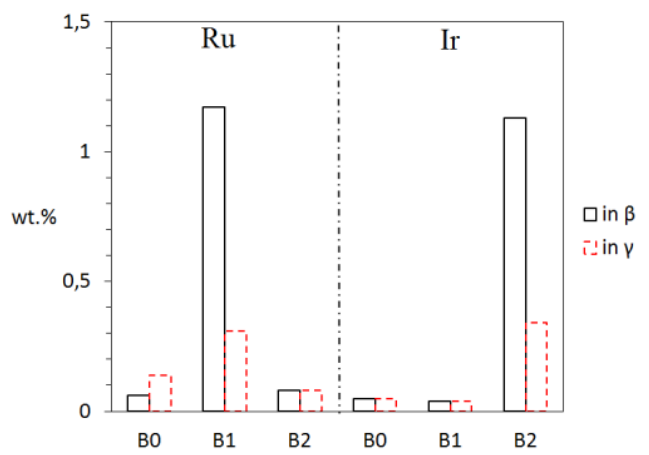

Figure 15. Concentrations of Ru and Ir in the $\beta$ and $\gamma$ phases in coatings after hot corrosion for 10 cycles, measured by EDS.

\section{Discussion}

The difference of the hot corrosion behaviour among the three coatings, B0, B1 and B2, was unlikely a coating composition effect, because the elements which caused the composition difference in the coatings, $\mathrm{Ta}, \mathrm{Ru}$ and $\mathrm{Ir}$, appeared to be inert in such hot corrosion condition. Those elements were oxidized only within the Al-depleted coating fragments and were dissolved in spinel phase. So, the different corrosion rate of the three coatings was related to their microstructures.

In the molten sulphate environment, the degradation of alumina scale formed either at the outmost coating surface or along the splat boundaries can be described by Eq. 1 according to the "fluxing" theory $[17,19-21] . \mathrm{Na}_{2} \mathrm{O}$ was a product from a reaction as shown in Eq. 2. The fluxing reaction in Eq. 1 can produce a porous, grain-refined, impure, and non-protective alumina scale [4,22]; the diffusion of ions from the 
atmosphere and the sulphate, like $\mathrm{O}$ and $\mathrm{S}$, became faster than in a pure oxidation environment [4].

$$
\begin{aligned}
& 2 \mathrm{Na}_{2} \mathrm{O}+2 \mathrm{Al}_{2} \mathrm{O}_{3}=4 \mathrm{NaAlO}_{2} \\
& \mathrm{Na}_{2} \mathrm{SO}_{4}=\mathrm{Na}_{2} \mathrm{O}+\mathrm{SO}_{3}(\mathrm{~g})
\end{aligned}
$$

Splat degradation further proceeded after the failure of alumina scale. Ions like oxygen (and nitrogen) easily diffused into the isolated splat (Fig. 9a) and caused the further oxidation (and nitridation) of $\mathrm{Al}$ until the $\mathrm{Al}$ content decreased under a certain level when other matrix elements $(\mathrm{Ni}, \mathrm{Co}, \mathrm{Cr})$ in the Al-depleted coating fragments (Fig. 9b) were oxidized to form spinel oxides.

The tested HVOF MCrAlY coatings in this study showed different quality of the splat boundary (with high or low porosity and intersplat-oxide amount) and the coating surface (dense or loose surface). The quality of the coating splat boundaries performed an important role in corrosive environments in HVOF coatings [11-13]. Coating B0 had the lowest porosity and intersplat oxides thus had the best splat boundary quality, and got the least attack from the hot corrosion environment forming the thinnest aluminadominant oxide layer and having the least spinel amount. B2 got a even heavier corrosion attack than B1, probably due to that the quality of B2's surface was poorer than B1. The small coating fragments at coating B2's surface (see Fig. 1c) provided more interfaces or boundaries which functioned similarly as intersplat boundaries easier to be attacked in the hot corrosion process. The difference of the coating quality may be related to the coating spraying process; however, which spraying parameter caused such difference was not investigated in this study. 


\section{Conclusions}

Hot corrosion behaviour of CoNiCrAlYSi coatings sprayed by HVOF was studied in an environment containing sodium-potassium sulphates at $900{ }^{\circ} \mathrm{C}$. In the molten sulphate condition, alumina scale became a non-protective mixed oxide layer. Microstructure results indicate that the hot corrosion preferentially occurred at surface, splat boundaries, or some interfaces. The coating with higher porosity and intersplat oxides amount, or with poorer coating surface (with additional interfaces or boundaries due to the existence of small coating fragments) tended to get a heavier corrosion attack due to a corrosion of the splats or the small coating fragments. This study suggests that the as-sprayed status of coatings should be taken care of when analyzing the coatings' behaviour in following high-temperature operations e.g. in hot corrosion processes.

\section{Acknowledgement}

The Siemens Industrial Turbomachinery AB (Finspang, Sweden) and Swedish Energy Agency through KME consortium - ELFORSK are greatly acknowledged for their financial support, $60 \%$ and $40 \%$ respectively, in this research. The research school of Agora Materials and Strategic Faculty Grant AFM in Linköping University are also acknowledged for their support on this research.

\section{References}

[1] N. Eliaz, G. Shemesh, R.M. Latanision, Hot corrosion in gas turbine components, Eng. Failure Anal. 9 (2002) 31-43. 
[2] Q.M. Wang, Y.N. Wu, P.L. Ke, H.T. Cao, J. Gong, C. Sun, L.S. Wen, Hot corrosion behavior of AIP NiCoCrAlY $(\mathrm{SiB})$ coatings on nickel base superalloys, Surf. Coat. Technol. 186 (2004) 389-397.

[3] M.N. Task, B. Gleeson, F.S. Pettit, G.H. Meier, Compositional effects on the Type I hot corrosion of $\beta-\mathrm{NiAl}$ alloys, Surf. Coat. Technol. 206 (2011) 1552-1557.

[4] C. Leyens, I.G. Wright, B.A. Pint, Hot corrosion of an EB-PVD thermal-barrier coating system at $950 \mathrm{deg}$ C, Oxid. Met. 54 (2000) 401-424.

[5] N.J. Simms, A. Encinas-Oropesa, J.R. Nicholls, Hot corrosion of coated and uncoated single crystal gas turbine materials, Mater. Corros. 59 (2008) 476-483.

[6] S. Pahlavanyali, A. Sabour, M. Hirbod, The hot corrosion behaviour of HVOF sprayed MCrAlX coatings under Na2SO4 $(+\mathrm{NaCl})$ salt films, Mater. Corros. 54 (2003) 687-693.

[7] J.T. DeMasi-Marcin and D.K. Gupta, Protective Coatings in the Gas Turbine Engine, Surf. Coat. Technol. 68/69 (1994) 1-9.

[8] H.E. Evans and M.P. Taylor, Oxidation of high-temperature coatings, Proceedings of the Institution of Mechanical Engineers G, Journal of Aerospace Engineering 220 (2006) 1-10.

[9] N. Czech, F. Schmitz, W. Stamm, Thermal mechanical fatigue behavior of advanced overlay coatings, Mater. Manuf. Process. 10 (1995) 1021-1035.

[10] D. Toma, W. Brandl, U. Köster, Studies on the transient stage of oxidation of VPS and HVOF sprayed MCrAlY coatings, Surf. Coat. Technol. 120-121 (1999) 8-15.

[11] W. Zhao, Y. Wang, L. Dong, K. Wu, J. Xue, Corrosion mechanism of NiCrBSi coatings deposited by HVOF, Surf. Coat. Technol. 190 (2005) 293-298.

[12] M.A. Uusitalo, P.M.J. Vuoristo, T.A. Mäntylä, High temperature corrosion of coatings and boiler steels in reducing chlorine-containing atmosphere, Surf. Coat. Technol. 161 (2002) 275-285.

[13] L. Gil and M.H. Staia, Influence of HVOF parameters on the corrosion resistance of NiWCrBSi coatings, Thin Solid Films 420-421 (2002) 446-454.

[14] C.H. Lee and K.O. Min, Effects of heat treatment on the microstructure and properties of HVOF-sprayed Ni-Cr-W-Mo-B alloy coatings, Surf. Coat. Technol. 132 (2000) 49-57.

[15] R. Eriksson, K. Yuan, X.-. Li, Lin Peng R., Corrosion of NiCoCrAlY Coatings and TBC Systems Subjected to Water Vapor and Sodium Sulfate, J. Therm. Spray Technol. DOI: $10.1007 / \mathrm{s} 11666-015-0253-\mathrm{z}$ (2015) 
[16] K. Yuan, R. Lin Peng, X. Li, S. Johansson, Y. Wang, Some aspects of elemental behaviour in HVOF MCrAlY coatings in high-temperature oxidation, Surf. Coat. Technol. 261 (2015) 86-101.

[17] R.A. Rapp, Hot Corrosion of Materials: A Fluxing Mechanism? Corros. Sci. 44 (2002) 209-221.

[18] N. Bornstein and M. DeCrescente, The role of sodium in the accelerated oxidation phenomenon termed sulfidation, Metall. Trans. 2 (1971) 2875-2883.

[19] J. Goebel and F. Pettit, Na2SO4-induced accelerated oxidation (hot corrosion) of nickel, Metall. Trans. 1 (1970) 1943-1954.

[20] J. Goebel, F. Pettit, G. Goward, Mechanisms for the hot corrosion of nickel-base alloys, Metall. Trans. 4 (1973) 261-278.

[21] R.A. Rapp, Chemistry and Electrochemistry of Hot Corrosion of Metals, Mater. Sci. Eng. 87 (1987) 319-327.

[22] K. Yuan, R. Lin Peng, X. Li, A. Talus, S. Johansson, Y. Wang, Hot corrosion of MCrAlY coatings in sulphate and SO2 environment at $900{ }^{\circ} \mathrm{C}$ : Is $\mathrm{SO} 2$ necessarily bad? Surf. Coat. Technol. 261 (2015) 41-53. 